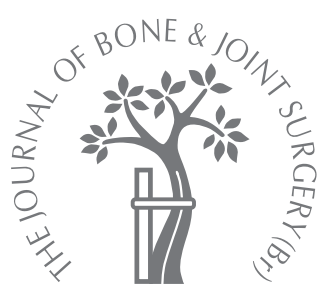

\title{
Short-term outcome in total knee replacement after soft-tissue release and balancing
}

\section{Unitt,}

A. Sambatakakis, D. Johnstone, T. W. R. Briggs and the Balancer Study Group

From Heart of England Foundation Trust, Birmingham, England

\begin{abstract}
We studied the influence of soft-tissue releases and soft-tissue balance on the outcome of 526 total knee replacements one year after operation. The surgery had been performed by seven surgeons in five centres in the United Kingdom between October 1999 and December 2002. Balancing was carried out by five surgeons using spacers and trials and by two surgeons using a 'balancer' instrument. All the surgeons assessed the adequacy of their releases by taking measurements with the balancer after soft-tissue release before implanting the components. Independent observers collected the Oxford knee scores and applied the American Knee Society functional and knee scores as well as recording the range of movement of the replaced knee. These were compared with the pre-operative scores and the extent of the releases.

We found differences in outcomes between minimal and extensive releases and between balanced and imbalanced knees.

Knees requiring extensive soft-tissue releases showed greater change in the short-term clinical outcome without increased complications and achieved similar results at one year compared with those with less deformity pre-operatively which had required less softtissue release. Balancing an imbalanced knee improved the short-term knee outcome.
\end{abstract}

Total knee replacement (TKR) is a common procedure with more than 53000 performed annually in the United Kingdom. ${ }^{1}$ Over the last 40 years there have been many advances in the design of implants, materials, instrumentation and surgical technique. However, certain key principles have remained unchanged including the importance of obtaining soft-tissue balance and correct alignment of the knee..$^{2-6}$

Long-term survival of the prosthesis in TKR is dependent on many variables which may be subdivided into patient and operative factors, the latter including the design of the implant and the operative technique. It is increasingly understood that the surgical balance of the TKR is essential for a successful outcome. In 1985 Insall $^{7}$ deemed the correct balance of the knee to be the most critical factor for the success of the operation. Previous work carried out by one of the senior authors (AS) has illustrated the detrimental effects of imbalance on the long-term survival in TKR. ${ }^{8}$ Other studies have reported similar findings and highlight that soft-tissue imbalance and bony malalignment in TKR lead to malfunction and failure. .,4,9-15 $^{2,15}$

Until recently, measuring the degree of balance intra-operatively has relied on a subjec- tive assessment by the operating surgeon. However, the requirement for more accurate measurement of the degree of balance of the knee at the time of surgery has led to the development of an instrument which allows objective measurements to be made in a reproducible manner. ${ }^{16}$

Balancing the arthritic knee by soft-tissue releases is technically demanding and is associated with a number of possible complications ${ }^{17}$ such as an increased risk of post-operative haematoma, wound complications and the subsequent risk of infection. Increasing the size of the flexion and extension gap after extensive releasing procedures may alter the position of the joint line, ${ }^{18}$ which in turn may have a detrimental effect on the range of movement and the function of the extensor mechanism ${ }^{19}$ and adversely affect the clinical outcome. ${ }^{20}$ It is not known whether extensive soft-tissue releases, carried out for long-term success, are compromised by short-term complications.

This multicentre project has been designed to study prospectively the influence of softtissue balancing on the outcome of TKR. Utilising the knee balancer instrument, we have investigated the effect of balance on the shortterm outcome after surgery. Further follow-up 
Table I. Clinical details of the 506 patients entered into the study

\begin{tabular}{lr}
\hline Mean age at operation in yrs (range) & 70 (40 to 90) \\
Gender & 230 (244 knees) \\
M & 276 (282 knees) \\
F & \\
Knee replacement & 486 (257 right, 229 left) \\
Unilateral & 40 (20 patients) \\
Bilateral & \\
& \\
Diagnosis (\%) & $483(91.9)$ \\
Osteoarthritis & $40(7.6)$ \\
Rheumatoid arthritis & $3(0.5)$ \\
Other & \\
Post-operative deformities (from radiological measurement) $\left({ }^{\circ}\right)\left(\mathrm{n}=501^{*}\right)$ & 385 (76.8) (-45 to +5) \\
Varus & $75(15.0)(+11$ to +38$)$ \\
Valgus & $41(8.2)(+5$ to +10$)$ \\
$\quad$ Normal alignment &
\end{tabular}

of the patients in this study will allow long-term results to be assessed. We have compared traditional methods of balancing of the knee with objective assessments, both before and after soft-tissue releases.

\section{Patients and Methods}

Between October 1999 and December 2002, we recruited 506 patients (526 knees) into a multicentre prospective study involving seven surgeons from five hospitals in the United Kingdom. The details of the patients are summarised in Table I. All those due to have a primary TKR were eligible for recruitment regardless of the pathology, except for those with a Charcot or ankylosed joint. Ethical approval was obtained and consent given by those included in the study.

Pre-operatively, the patients were assessed using the Oxford knee score (OKS), ${ }^{21}$ the American Knee Society clinical rating system ${ }^{22}$ and the roentgenographic and evaluation scoring system. ${ }^{23}$ In all the patients standard weightbearing plain radiographs were taken. The pre-operative deformity and range of movement (ROM) were measured using a standard goniometer (Physio Med Services Ltd, Glossop, United Kingdom). Surgery was undertaken by seven surgeons experienced in knee replacement and the intra-operative details and measurements were recorded. Post-operatively, measurement of the knee scores was repeated and complications were documented. All the assessments were performed by three independent, trained observers (LU). These were repeated at six and 12 months and will continue annually.

The balancer (Stryker UK, Newbury, United Kingdom; Fig. 1) consists of two metal plates which are inserted into the knee after the initial bony cuts on the tibia and femur have been made. The plates sit flat against the cut surfaces of the distal and posterior femur and proximal tibia. On turning the handle clockwise the integral rack-and-pinion tensing mechanism distracts the plates with the effect of tensioning the soft tissues. There is a central scale on the balancer which measures the degree of distraction in millimetres between the plates, hence assessing the flexion and extension gaps. As the two plates are distracted, the upper plate is free to pivot centrally in the coronal plane under the influence of any tension in the soft tissues and thus demonstrate the degree of imbalance between the medial and lateral structures. Measurements are recorded in degrees on a scale from 0 to 12 on a platform/dial attached to the upper plate. Any deviation to the medial side is defined as varus and designated a minus sign and to the lateral side as valgus and designated a plus sign. ${ }^{16,24,25}$

In all cases a Kinemax Plus Total Condylar cemented knee prosthesis (Stryker UK) was implanted, and all the surgeons used identical bone-cutting instrumentation, cementing technique and similar post-operative rehabilitation.

The balance of the knee was assessed in two positions, first in full extension and then in $90^{\circ}$ of flexion to determine both the flexion and extension gaps. However, the surgeons used different surgical techniques to obtain balance of the knee, with five employing trial components, spacers, or a calibrated measuring device (Gobot, Stryker UK) to equalise the flexion and extension gaps as judged from the intermedullary canal and posterior condyles. The remaining two surgeons who had previous experience in the use of the balancer instrument undertook measurements of balance after the distal and posterior femoral and proximal tibial cuts had been made. Depending on the measurements obtained, soft-tissue releases were performed as required, until the measured balance was achieved. All the surgeons recorded the soft-tissue releases performed to balance the knee whichever method was used. Following the definitive bone cuts and completion of all soft-tissue releases, they all 

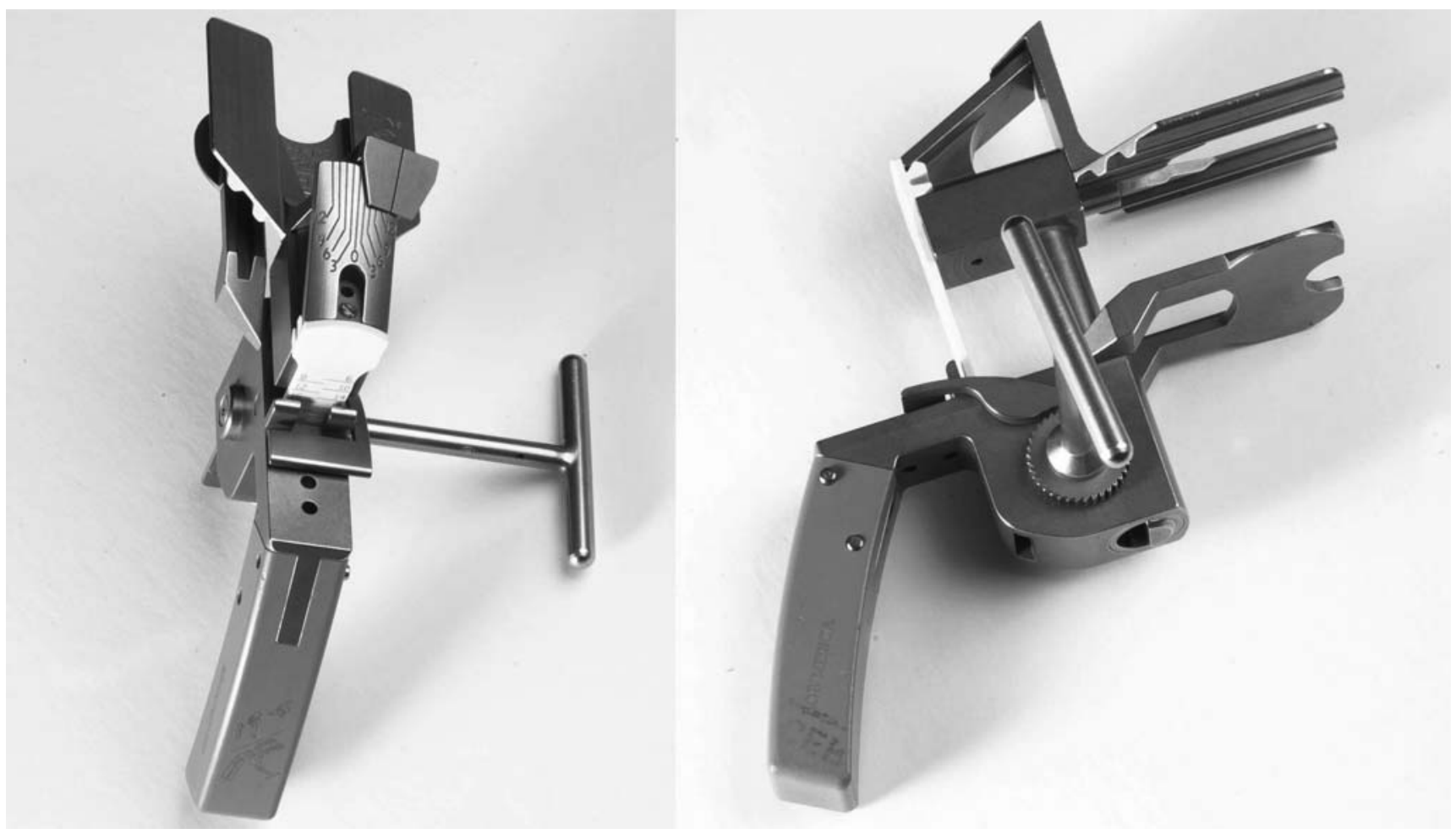

Fig. 1

Photographs of the balancer.

\begin{tabular}{|c|c|}
\hline \multicolumn{2}{|c|}{ Soft-tissue releases } \\
\hline \multicolumn{2}{|l|}{ None/miminal } \\
\hline Medial & None/capsule and deep medial ligament (part of incision for exposure) \\
\hline Lateral & None \\
\hline \multicolumn{2}{|l|}{ Moderate } \\
\hline Medial & All previous plus superficial medial ligament and/or pes anserinus partial \\
\hline Lateral & Iliotibial band and/or lateral collateral ligament \\
\hline \multicolumn{2}{|l|}{ Extensive } \\
\hline Medial & All previous plus pes anserinus complete and/or any semimembranosus \\
\hline Lateral & All previous plus popliteus, lateral gastrocnemius and/or biceps femoris \\
\hline \multicolumn{2}{|c|}{ Soft-tissue balance } \\
\hline Balanced & Balancer measurements -3 to +3 \\
\hline Imbalanced & Balancer measurements outside of -3 to +3 \\
\hline
\end{tabular}

undertook a final assessment of the balance obtained using the balancer instrument and recorded their findings, before cementing the components. Balance was defined as a range between $-3^{\circ}$ and $+3^{\circ}$.

Statistical analysis. Collection and analysis of the data were performed using SPSS version 12 (SPSS Inc., Chicago, Illinois). The outcome measures and complications were assessed in three different ways. First, they were analysed according to the extent of the soft-tissue releases which were classified into none/minimal, moderate, or extensive according to the structures released (Table II). The second analysis was performed according to the amount of softtissue balance achieved and then thirdly, according to the surgical technique. Analysis of variance (ANOVA) was used to assess the difference between three or more groups with the post hoc Tukey test showing any significance. An 
Table III. Mean (SD) for each of the Oxford knee score (OKS) and the American knee society clinical rating scores and a range of movement for each of the soft-tissue release groups (410 knees at 12 months)

\begin{tabular}{|c|c|c|c|c|c|c|c|}
\hline & \multicolumn{2}{|l|}{ Group 1} & \multicolumn{2}{|l|}{ Group 2} & \multicolumn{2}{|l|}{ Group 3} & \multirow[b]{2}{*}{$\begin{array}{l}\text { p-value } \\
\text { (ANOVA* }\end{array}$} \\
\hline & $\begin{array}{l}\text { None/minima } \\
\text { releases } \\
\text { (173 knees) }\end{array}$ & SD & $\begin{array}{l}\text { Moderate } \\
\text { releases } \\
\text { (122 knees) }\end{array}$ & SD & $\begin{array}{l}\text { Extensive } \\
\text { releases } \\
\text { (115 knees) }\end{array}$ & & \\
\hline \multicolumn{8}{|l|}{ OKS } \\
\hline Pre-operative & 43.0 & (7.4) & 42.8 & $(7.3)$ & 43.0 & $(7.8)$ & 0.984 \\
\hline 12 months & 24.9 & (9.5) & 24.1 & (9.3) & 22.0 & $(7.8)$ & 0.025 \\
\hline Change & 18.0 & $(10.4)$ & 18.7 & (9.6) & 21.0 & $(8.1)$ & 0.029 \\
\hline \multicolumn{8}{|c|}{ Clinical rating knee score } \\
\hline Pre-operative & 45.5 & $(17.5)$ & 41.3 & $(19.1)$ & 30.8 & $(20.7)$ & 0.000 \\
\hline 12 months & 86.1 & $(13.9)$ & 87.7 & $(13.4)$ & 87.7 & (11.9) & 0.458 \\
\hline Change & 40.6 & $(21.7)$ & 46.4 & $(21.9)$ & 56.9 & $(22.3)$ & 0.000 \\
\hline \multicolumn{8}{|c|}{ Clinical rating functional score } \\
\hline Pre-operative & 47.5 & $(17.1)$ & 44.5 & $(16.3)$ & 43.1 & (17.9) & 0.082 \\
\hline 12 months & 67.0 & $(22.5)$ & 68.9 & $(22.7)$ & 69.7 & (23.8) & 0.0586 \\
\hline Change & 19.5 & $(18.5)$ & 24.4 & $(19.1)$ & 26.5 & $(19.8)$ & 0.006 \\
\hline \multicolumn{8}{|c|}{ Range of movement $\left({ }^{\circ}\right)$} \\
\hline Pre-operative & 97.5 & $(17.0)$ & 96.0 & $(19.2)$ & 93.0 & $(21.0)$ & 0.118 \\
\hline 12 months & 103.0 & $(13.5)$ & 103 & $(13.5)$ & 104.5 & (11.5) & 0.573 \\
\hline Change & 5.3 & $(18.4)$ & 8.4 & $(21.4)$ & 12.8 & (20.5) & 0.003 \\
\hline
\end{tabular}

* ANOVA, analysis of variance

Table IV. Mean (SD) change in outcome measures for the change in extension balance groups (214 knees from subset of 218)

\begin{tabular}{|c|c|c|c|}
\hline & Group a & Group c & \\
\hline & $\begin{array}{l}\text { Balance before release and } \\
\text { remained balanced }(n=93)\end{array}$ & $\begin{array}{l}\text { Imbalanced before release and } \\
\text { balanced intra-operatively }(n=121)\end{array}$ & $\begin{array}{l}\text { p-value } \\
\text { (t-test) }\end{array}$ \\
\hline Change in mean Oxford knee score & $19.2(9.4)$ & $19.4(8.3)$ & 0.112 \\
\hline Change in mean clinical rating knee score & $45.2(20.6)$ & $51.6(24.6)$ & 0.046 \\
\hline Change in mean clinical rating functional score & $21.6(16.3)$ & $23.3(20.1)$ & 0.506 \\
\hline Change in mean range of movement & $7.46(18.2)$ & $9.32(20.7)$ & 0.518 \\
\hline
\end{tabular}

independent $t$-test was used for the analysis of the two groups of the data set. Statistical significance was defined as $\mathrm{p} \leq 0.05$.

\section{Results}

Of the original 526 knees, 410 (394 patients) were available for review after 12 months. Nine patients (11 knees) had died from unrelated causes, seven (eight knees) had moved away from the area, seven (eight knees) had withdrawn because of other illnesses and five (five knees) had a revision (three for infection, one for loosening and one for unexplained pain). In addition, 14 patients (14 knees) had been lost to follow-up because of persistent non-attendance for review. Five (five knees) no longer wished to keep attending and withdrew from the study, but indicated their satisfaction with their TKR. One centre recruited private patients to the study who lived some distance from the main hospital and five (five knees) of these withdrew because of the travel requirement. A further 60 patients $(60$ knees) were unable to attend for the 12-month review for a number of reasons, but have subsequently attended or been contacted by telephone. Any complications were recorded. Only six of these 60 patients still had moderate pain or difficulty with their knee at 12 months after operation, as assessed by the OKS.

When considering the entire cohort (410 knees), the mean OKS improved from a pre-operative score of 42.74 (SD 7.33) to 23.87 (SD 9.02) post-operatively. Likewise, the mean American Society clinical rating knee score increased from 40.25 (SD 19.52) pre-operatively to 87.02 (SD 13.21) post-operatively with the mean range of movement increasing from $90.5^{\circ}\left(\mathrm{SD} 20.5^{\circ}\right)$ to $103^{\circ}$ (SD $\left.13.05^{\circ}\right)$. At 12 months the mean functional score had improved from 45.62 (SD 17.76) pre-operatively to a mean post-operative score of 68.22 (SD 22.89).

Analysis of outcome in relation to the soft-tissue releases performed. The knees were grouped according to the extent of the soft-tissue release. 
Table V. Mean (SD) change in Oxford knee score and American Knee Society clinical rating scores and mean range of movement for the change in flexion balance groups (subset of 218 knees)

\begin{tabular}{|c|c|c|c|c|c|}
\hline \multirow[b]{2}{*}{ Group } & $\mathbf{i}$ & ii & \multicolumn{2}{|c|}{ iii iv } & \multirow[b]{2}{*}{$\begin{array}{l}\text { p-value } \\
\text { (ANOVA*) }\end{array}$} \\
\hline & $\begin{array}{l}\text { Balanced before } \\
\text { release and remained } \\
\text { balanced }(n=92)\end{array}$ & $\begin{array}{l}\text { Balanced before } \\
\text { release and became } \\
\text { imbalanced }(n=18)\end{array}$ & $\begin{array}{l}\text { Imbalanced before } \\
\text { release and remained } \\
\text { imbalanced }(n=25)\end{array}$ & $\begin{array}{l}\text { Imbalanced before } \\
\text { release and became } \\
\text { balanced }(n=83)\end{array}$ & \\
\hline Change in mean Oxford knee score & $19.61(9.14)$ & $20.67(7.38)$ & $19.52(9.86)$ & $18.36(8.34)$ & 0.686 \\
\hline Change in mean clinical rating knee score & $43.09^{\dagger}(22.46)$ & $65.22(22.08)$ & $54.40(20.80)$ & $49.04(23.08)$ & 0.001 \\
\hline $\begin{array}{l}\text { Change in mean clinical rating functional } \\
\text { score }\end{array}$ & $19.18(15.71)$ & $29.44(0.14)$ & $25.80(19.98)$ & $23.67(20.29)$ & 0.086 \\
\hline Change in mean range of movement & $7.08^{\dagger}(18.98)$ & $22.78(25.16)$ & $1.92(18.63)$ & $8.84(21.72)$ & 0.010 \\
\hline
\end{tabular}

* ANOVA, analysis of variance

$\dagger$ significant at $p \leq 0.05$

There were 173 knees with none or only minimal releases (group 1), 122 knees with moderate releases (group 2) and 115 knees with extensive releases (group 3).

The mean (SD) pre-operative and 12-month scores for the $\mathrm{OKS}$ and the American Knee Society clinical rating system, as well as the change in mean outcome scores are shown in Table III.

There was a significant difference in the change in the mean OKS between groups 1 and 3 (ANOVA $p=0.029$ ). Likewise, the clinical rating system showed a highly significant difference for the knee score and functional score between groups 1 and 3 (ANOVA, $\mathrm{p}=0.000, \mathrm{p}=0.006$ ), respectively. The same groups also showed a significant difference in the mean ROM (ANOVA, $p=0.003$ ). If examined separately, the results were more marked for the valgus knees requiring lateral releases (ANOVA, OKS, $\mathrm{p}=0.037$, knee score, $\mathrm{p}=0.000$, functional score, $\mathrm{p}=0.017$, ROM, $\mathrm{p}=0.001$ ). A highly significant difference was shown for the pre-operative mean clinical rating knee scores (ANOVA, $\mathrm{p}=0.000$ ) between the soft-tissue release groups. Analysis of outcome in relation to the soft-tissue balance achieved. With regard to the extent of balance achieved, both the flexion and extension balance were assessed. For the purpose of analysis, balance was defined as three degrees either side of $0(-3$ to +3$)$. All surgeons recorded balancer measurements pre-cementation (post releases) and no difference was apparent between the balanced or the imbalanced groups relating to outcome when studying the entire cohort (balanced in extension, $\mathrm{n}=444$, imbalanced $n=82$; balanced in flexion, $n=394$, imbalanced $n=132$; balanced in both, $n=358$; balanced in neither $\mathrm{n}=169$ ).

Two surgeons recorded measurements after bony resection to quantify how unbalanced the knees were before undertaking any soft-tissue release. This subset of 218 knees was analysed, comparing the balance of the knee before and after soft-tissue releases. Within this subset, three groups were identified according to the extension balance as follows:

a) 93 balanced knees soft-tissue release which remained so in extension post-operatively; b) four imbalanced knees before release which remained so to some extent post-operatively; and

c) 121 imbalanced knees before release which were balanced in extension post-operatively.

Analysis was performed for all three groups and repeated with group b excluded to provide greater comparability of the number of knees in each group and to prevent the skewing of data. The change in scores for the mean OKS and the American Knee Society clinical rating system are shown in Table IV.

There was no significant difference between the change in the mean OKS, the mean clinical rating functional score, the mean ROM and the amount of extension balance achieved $(t$-test, $\mathrm{p}=0.873, \mathrm{p}=0.506$ and $\mathrm{p}=0.518$, respectively). However, there was a significant difference with the change in the clinical rating knee score $(t$-test, $\mathrm{p}=0.046)$. The knees left imbalanced $(n=4)$ had substantially lower changes in the mean scores (ANOVA, $p=0.037$ ). Those knees imbalanced initially but balanced post-operatively showed the greatest improvement (knee score, $t$-test; $\mathrm{p}=$ 0.046). Exclusion of group $b$ made no difference to the overall statistical significance. Analysis of the mean preoperative clinical rating knee scores revealed a significant difference between group a, balanced knees before release, and group e, imbalanced knees before release ( $t$-test, $\mathrm{p}=$ 0.033).

With regard to flexion balance, four groups were identified as follows:

i) balanced knees before release which remained so in flexion post-operatively $(\mathrm{n}=92)$;

ii) balanced knees in flexion before release which became imbalanced post-operatively $(\mathrm{n}=18)$;

iii) imbalanced knees before release which remained so to some degree post-operatively $(\mathrm{n}=25)$; and

iv) imbalanced knees before release which were balanced in flexion post-operatively $(\mathrm{n}=83)$.

As with extension balance there was no significant difference between the change in OKS or clinical rating functional scores regardless of the amount of flexion balance achieved (ANOVA, $\mathrm{p}=0.686$ and $\mathrm{p}=0.086$, respectively). However, a significant difference was found in both the 
clinical rating knee score and the range of movement (ANOVA, $p=0.001$ and $p=0.010$, respectively) between balanced and imbalanced knees (Table V).

By contrast, analysis of the mean pre-operative clinical rating knee scores showed a highly significant difference between the balanced and imbalanced group (ANOVA, $\mathrm{p}=0.000)$. This difference between the pre-operative scores between the balanced and imbalanced groups in flexion was similar to the pre-release extension differences with imbalanced knees being initially worse but showing no difference at 12 months after operation.

Analysis of outcome in relation to surgical technique. The knees were split into two groups according to when during the operation the measurements and soft-tissue releases were undertaken. No significant difference could be seen between the change in outcome measure scores with either technique $(t$-test, OKS, $\mathrm{p}=0.052$, American knee society clinical rating, $\mathrm{p}=0.318$, American knee society functional rating, $\mathrm{p}=0.164$, $\mathrm{ROM}, \mathrm{p}=0.670)$.

Complications. Superficial wound discharge occurred in 36 patients but only three required early revision for deep infection. Two other knees were revised, one for loosening and the other for unexplained pain. Formation of a haematoma occurred in 12 knees, of which six required evacuation. Manipulation under anaesthetic was necessary in 27 knees (27 patients) because of stiffness with a range of movement $>75^{\circ}$. There were two deaths within 30 days of surgery. There were 12 cases of symptomatic deep-vein thrombosis, four of non-fatal pulmonary embolus, nine of myocardial infarction, four of pseudo-obstruction and one of a perforated bowel, all of which occurred within the first 12 months after surgery.

No association could be identified between any of the complications, and the extent of release required, the softtissue balance achieved or the surgical technique performed.

\section{Discussion}

Freeman et $\mathrm{al}^{2}$ and Insall ${ }^{26}$ emphasised the concept of softtissue balancing and introduced the use of a spacer-tensor device to assess the symmetry of the flexion and extension gaps. They stated that correct soft-tissue balancing would increase longevity and decrease revision rates in TKR.

Sambatakakis et al, ${ }^{8}$ described the cement wedge sign which is the presence of a smoothly tapering wedge of cement beneath the horizontal portion of the tibial component on anteroposterior radiographs indicating persistent soft-tissue imbalance and associated with a highly significant increase in radiolucent lines at the cement-bone interface of the tibia at follow-up.

It has been reported that instability after operation is often caused by incorrect balancing of the ligaments. ${ }^{27}$ The relationship between the adequacy of ligament release and the severity of polyethylene wear, found at revision, was confirmed by Wasielewski et al. ${ }^{9}$ Residual imbalance was associated with loosening, polyethylene wear and failure.
Attfield et $\mathrm{al}^{28}$ reported that knees balanced in both full extension and in flexion showed improved proprioception post-operatively, whereas those balanced in extension only did not. Mihalko, Whiteside and Krackow ${ }^{29}$ also believe that knees should be balanced in both flexion and extension, but it has been questioned whether rectangular gaps are the ideal goal since the knee joint is trapezoidal in shape. ${ }^{30}$

It is generally recognised that ligament releases should be selective ${ }^{31}$ and the sequence of releases can dramatically alter the soft-tissue balance and stability of the knee. ${ }^{27,29,32}$ A small degree of imbalance may be tolerable $\mathrm{e}^{33}$ if alignment is good, ${ }^{34}$ particularly since perfect balance is difficult to achieve. $^{35}$

We have demonstrated that the amount of soft-tissue release performed at the time of surgery has a significant effect on both clinical and functional outcomes. Patients undergoing extensive releases showed a significantly greater change in short-term outcomes, including ROM, such that their outcomes at 12 months were equivalent to those of patients undergoing minimal releases. This is contrary to the traditionally perceived view that performing extensive releases would lead to a poorer clinical outcome. ${ }^{20}$ One previous study reported that the knees most severely affected pre-operatively, despite showing good improvement, have a poorer outcome than less affected knees and concluded that certain pre-operative factors must influence outcome. ${ }^{36}$ Our study suggests that this is not the case in the short-term, since no difference was seen in the clinical outcome at 12 months in any of our groups. Patients who underwent an extensive soft-tissue release had as good an outcome and an equivalent ROM and incidence of complications as those who required minimal or no soft-tissue release. This is contrary to the findings of others. ${ }^{18,19}$

We recognise the limitations of our study since a sizeable number of patients did not attend for their assessments at 12 months. However, the outcome assessments were carried out by independent observers.

The pioneers of condylar TKR expressed the view that correct soft-tissue balancing would increase the longevity and decrease revision rates, especially in the challenging group of young and heavier patients. It was felt that too high a price would be paid in the short-term in order to achieve this long-term aim. However, our analysis of softtissue balancing in TKR has shown that in the short term, knees requiring extensive soft-tissue releases have a significantly greater change in clinical outcome and have comparable results to those requiring minimal releases, without leading to increased complications. We have also shown that balancing an imbalanced knee significantly improves the outcome. It remains to be seen whether balancing these knees will lead a better outcome in the longer term.

The authors wish to acknowledge the work of the Balancer Study group: S. Cannon, M. Needoff, I. S. Fyfe, B. J. McElroy, R. Jackson, P. Thornton-Bott, B. Rogers, J. Jagiello, S. Isopescu. This project has been supported and funded by Stryker UK. 
Although none of the authors have received or will receive benefits for personal or professional use from a commercial party related directly or indirectly to the subject of this article, benefits have been or will be received but will be directed solely to a research fund, foundation, educational institution, or other non-profit organisation with which one or more of the authors are associated.

\section{References}

1. No authors listed. National Joint Registry for England and Wales, 4th Annual Report, 2007:89.

2. Freeman MA, Todd RC, Bamert P, Day WH. ICLH Arthroplasty of the knee: 19681977. J Bone Joint Surg [Br] 1978;60-B:339-44.

3. Insall J, Tria AJ, Scott WN. The total condylar knee prosthesis: the first 5 years. Clin Orthop 1979;145:68-77.

4. Insall JN, Binazzi R, Soudry M, Mestriner LA. Total knee arthroplasty. Clin Orthop 1985;192:13-22.

5. Vince KG, Insall JN, Kelly MA. The total condylar prosthesis: 10-12 year results of a cemented knee replacement. J Bone Joint Surg [Br] 1989;71-B:793-7.

6. Ranawat CS, Flynn WF Jr, Saddler S, Hansraj KK, Maynard MJ. Long-term results of the total condylar arthroplasty: a 15 year survivorship study. Clin Orthop 1993;286:94-102.

7. Insall JN. Correction of arthritic deformities of the knee. In: McCarty DJ, ed. Arthritis and allied conditions: a textbook of rheumatology. Tenth ed. Philadelphia: Lea and Febiger, 1985:771-84.

8. Sambatakakis A, Wilton TJ, Newton G. Radiographic sign of persistent soft-tissue imbalance after knee replacement. J Bone Joint Surg [Br] 1991;73-B:751-6.

9. Wasielewski RC, Galante J0, Leighty RM, Natarajan RN, Rosenberg AG. Wear patterns on retrieved polyethylene tibial inserts and their relationship to technical considerations during total knee arthroplasty. Clin Orthop 1994;299:31-43.

10. Windsor RE, Scuderi GR, Moran MC, Insall JN. Mechanism of failure of the femoral and tibial components in total knee arthroplasty. Clin Orthop 1989;248:1519

11. Lotke PA, Ecker ML. Influence of positioning of the prosthesis in total knee replacement. J Bone Joint Surg [Am] 1977; 59-A:77-9.

12. Karachalios T, Sarangi PP, Newman JH. Severe varus and valgus deformities treated by total knee arthroplasty. J Bone Joint Surg [Br] 1994;76-B:938-42.

13. Teeny SM, Krackow KA, Hungerford DS, Jones M. Primary total knee arthroplasty in patients with severe varus deformity: a comparative study. Clin Orthop 1991;273:19-31.

14. Dorr LD, Boiardo RA. Technical considerations in total knee arthroplasty. Clin Orthop 1986;205:5-11.

15. Matsuda S, Miura H, Nagamine R, et al. Changes in knee alignment after total knee arthroplasty. J Arthroplasty 1999;14:566-70.

16. Sambatakakis A, Attfield SF, Newton G. Quantification of soft-tissue imbalance in condylar knee arthroplasty. J Biomed Eng 1993:15:339-43.
17. Kumar PJ, Dorr LD. Severe malalignment and soft-tissue imbalance in total knee arthroplasty. Am J Knee Surg 1997;10:36-41.

18. Yoshii I, Whiteside LE, White SE, William MT. Influence of prosthetic joint line position on knee kinematics and patellar position. J Arthroplasty 1991;6:169-77.

19. Walker PS, Garg A. Range of motion in total knee arthroplasty: a computer analysis. Clin Orthop 1991;262:227-35.

20. Martin JW, Whiteside LA. The influence of joint line position on knee stability afte condylar knee arthroplasty. Clin Orthop 1990;259:146-56.

21. Dawson J, Fitzpatrick R, Murray D, Carr A. Questionnaire on the perceptions of patients about total knee replacement. J Bone Joint Surg [Br] 1998;80-B:63-9.

22. Insall JN, Dorr LD, Scott RD, Scott WN. Rationale of the knee society clinical rating system. Clin Orthop 1989;248:13-14.

23. Ewald FC. The knee society total knee arthroplasty roentgenographic evaluation and scoring system. Clin Orthop 1989;248:9-12.

24. Wilton TJ, Sambatakakis A, Attfield SF. Soft-tissue balancing at the time of knee replacement: rationale and method. The Knee 1994;1:111-16.

25. Attfield SF, Warren-Forward M, Wilton T, Sambatakakis A. Measurement of soft tissue imbalance in total knee arthroplasty using electronic instrumentation. Med Eng Phys 1994;16:501-5

26. Insall JN, ed. Surgery of the knee. New York: Churchill Livingstone, 2000:1558-62.

27. Takahashi T, Wada Y, Yamamoto H. Soft-tissue balancing with pressure distribution during total knee arthroplasty. J Bone Joint Surg [Br] 1997;79-B:235-9.

28. Attfield SF, Wilton TJ, Pratt DJ, Sambatakakis A. Soft tissue balance and recovery of proprioception after total knee replacement. J Bone Joint Surg [Br] 1996;78B:540-5.

29. Mihalko WM, Whiteside LA, Krackow KA. Comparison of ligament-balancing techniques during total knee arthroplasty. J Bone Joint Surg [Am] 2003;85-A(Supp 4):132-5.

30. Tokuhara Y, Kadoya Y, Nakagawa S, Kobayashi A, Takaoka K. The flexion gap in normal knees: an MRI study. J Bone Joint Surg [Br]2004;86-B:1133-6.

31. Whiteside LA. Soft tissue balancing: the knee. J Arthroplasty2002;17(Suppl 1):23-7.

32. Krackow KA, Miller CD, Mihalko WM, et al. Thinking about deformity and alignment in TKA. Orthopedics 1997;20:825-6.

33. Moreland JR. Mechanisms of failure in total knee arthroplasty. Clin Orthop 1991;273:49-64.

34. Engh GA, Moreland JR, Rorabeck CH, Volz RG. The AMK total knee system: surgical technique. Leeds, United Kingdom: DePuy International Ltd, 1989.

35. Griffin FM, Insall JN, Scuderi GR. Accuracy of soft tissue balancing in total knee arthroplasty. J Arthroplasty 2000;15:970-3.

36. Lingard EA, Katz JN, Wright EA, Sledge CB. Kinemax outcomes group: predicting the outcome of total knee arthroplasty. J Bone Joint Surg [Am] 2004;86-A:2179-86. 